\title{
Overexpression of SOCS3 exhibits preclinical antitumor activity against malignant pleural mesothelioma
}

\author{
Kota Iwahori ${ }^{1,2}$, Satoshi Serada ${ }^{1}$, Minoru Fujimoto ${ }^{1}$, Shintaro Nomura ${ }^{3}$, Tadashi Osaki ${ }^{2}$, Chun Man Lee ${ }^{4}$, \\ Hiroyuki Mizuguchi ${ }^{5}$, Tsuyoshi Takahashi ${ }^{1}$, Barry Ripley ${ }^{6}$, Meinoshin Okumura ${ }^{7}$, Ichiro Kawase ${ }^{2}$, Tadamitsu Kishimoto ${ }^{6}$ and \\ Tetsuji Naka ${ }^{1}$ \\ ${ }^{1}$ Laboratory for Immune Signal, National Institute of Biomedical Innovation, Osaka, Japan \\ ${ }^{2}$ Department of Respiratory Medicine, Allergy, and Rheumatic Diseases, Osaka University Graduate School of Medicine, Osaka, Japan \\ ${ }^{3}$ Faculty of Animal Bioscience, Nagahama Institute of Bio-Science and Technology, Shiga, Japan \\ ${ }^{4}$ Medical Center for Translational Research, Osaka University Hospital, Osaka, Japan \\ ${ }^{5}$ Laboratory of Gene Transfer and Regulation, National Institute of Biomedical Innovation, Osaka, Japan \\ ${ }^{6}$ Laboratory of Immune Regulation, Osaka University Graduate School of Frontier Biosciences, Osaka, Japan \\ ${ }^{7}$ Department of General Thoracic Surgery, Osaka University Graduate School of Medicine, Osaka, Japan
}

Malignant pleural mesothelioma (MPM) is an aggressive tumor with poor prognosis for which an effective therapy remains to be established. Our study investigated the therapeutic potential of the suppressor of cytokine signaling 3 (SOCS3), an endogenous inhibitor of intracellular signaling pathways, for treatment of MPM. We infected MPM cells (H226, EHMES-1, MESO-1 and MESO-4) with an adenovirus-expressing SOCS3 (AdSOCS3) to examine the effect of SOCS3 overexpression on MPM cells. SOCS3 overexpression reduced MPM proliferation and induced apoptosis and partial G0/G1 arrest. SOCS3 also inhibited the proliferation of MPM cells via multiple signaling pathways including Janus kinase (JAK)/signal transducer and activator of transcription 3 (STAT3), extracellular signal-regulated kinase (ERK), focal adhesion kinase (FAK) and p53 pathways. Notably, AdSOCS3 treatment inhibited tumor growth in an MPM pleural xenograft model. These findings demonstrate that overexpression of SOCS3 has a potent antitumor effect against MPM both in vitro and in vivo and indicate the potential for clinical use of SOCS3 for MPM treatment.

Malignant pleural mesothelioma (MPM) is an aggressive tumor arising from the mesothelial cells of serosal cavities. MPM may be asymptomatic at the early stage and is sometimes observed incidentally during routine chest radiography. Common symptoms include chest pain and dyspnea, which are caused by tumor invasion of the chest wall or pleural effusion and occur late during disease progression. Although chemotherapy with the drug pemetrexed improves survival time for unresectable MPM patients, the overall median survival time is only 12 months. ${ }^{1}$ MPM is often associated with past exposure to asbestos, in which case there is a long latency period, often exceeding 20 years, between first exposure to asbestos and diagnosis of MPM. ${ }^{2}$ The number of deaths from MPM is expected to increase in the next 20 years world-wide where heavy use of asbestos has occurred. ${ }^{2-5}$ There is thus a growing need for the development of new therapies to treat this disease.

A growing number of studies of MPM tumor biology have established important roles for cytokines involved in tumor growth or the spread of this disease. ${ }^{6-10}$ A reported potential molecular target for MPM therapeutics is the interleukin-6 (IL-6)/Janus kinase (JAK)/signal transducer and activator of transcription 3 (STAT3) signaling pathway and

Key words: malignant pleural mesothelioma, suppressor of cytokine signaling 3, gene therapy, signal transducer and activator of transcription 3, p53

Abbreviations: 7-AAD: 7-amino-actinomycin D; DAPI: 4',6-diamidino-2-phenylindole; DMSO: dimethyl sulfoxide; ERK: extracellular signalregulated kinase; FAK: focal adhesion kinase; FCS: fetal calf serum; IL-6: interleukin-6; JAK: Janus kinase; MPM: malignant pleural mesothelioma; MOI: multiplicity of infection; MRA: anti-IL-6 receptor antibody; MTS: 3-(4,5-dimethylthiazol-2-yl)-5-(3-carboxymethoxyphenyl)-2-(4-sulfophenyl)-2H-tetrazolium; pfu: plaque-forming units; PI: propidium iodide; SH2: Src homology 2; SHP: SH2-domaincontaining tyrosine phosphatase; siRNA: small interfering RNA; SOCS3: suppressor of cytokine signaling 3; STAT3: signal transducer and activator of transcription 3; TUNEL: Terminal deoxynucleotidyl transferase-mediated dUTP nick-end labeling

Grant sponsor: Ministry of Health, Labour and Welfare, Japan, Ministry of Education, Culture, Sports, Science and Technology, Japan DOI: $10.1002 / \mathrm{ijc} .25716$

History: Received 15 Jun 2010; Accepted 22 Sep 2010; Online 14 Oct 2010

Correspondence to: Tetsuji Naka, Laboratory for Immune Signal, National Institute of Biomedical Innovation, 7-6-8 Saito-Asagi, Ibaraki, Osaka 567-0085, Japan, Tel.: +81-72-641-9843, Fax: +81-72-641-9837, E-mail: tnaka@nibio.go.jp 
high-level expression of IL-6 in the pleural fluid of MPM patients. ${ }^{11,12}$ The binding of IL- 6 to its cognate receptor leads to a conformational change in the receptor that initiates the activation of JAK, which in turn activates the transcription factor STAT3 to dimerize and translocate into the nucleus, thus leading to the initiation of target gene transactivation. This pathway is crucial for the occurrence of hematopoiesis, immune response and oncogenesis. ${ }^{13}$ Moreover, dysfunction of the regulatory system for the JAK/STAT3 pathway has been demonstrated to be involved in the development of cancer. $^{13}$

The suppressor of cytokine signaling (SOCS) family proteins ${ }^{14-16}$ participate in the negative regulation of multiple signaling pathways including the IL-6/JAK/STAT3 signaling pathway, ${ }^{17-19}$ while SOCS3 can bind both the cytokine receptor and JAK, thus facilitating inhibition of the JAK molecule. $^{20}$ The restoration of SOCS3 expression in several cancer cell lines was found to effectively suppress tumorigenicity. ${ }^{21}$ Because the JAK/STAT3 signaling pathway is frequently activated in a wide variety of human malignancies, ${ }^{22}$ SOCS3 gene delivery may represent a novel therapeutic strategy for the treatment of human cancers, including mesothelioma.

In addition to the IL-6/JAK/STAT3 signaling pathway, various other signaling pathways are associated with tumorigenesis in MPM. Among these pathways, activators of oncogenic molecules such as the extracellular signal-regulated kinase (ERK) and focal adhesion kinase (FAK) have been implicated. $^{23,24}$ It was reported that SOCS3 participated in the inhibition of ERK phosphorylation and the degradation of FAK $^{25-27}$ SOCS3 can competitively block receptor recruitment of $\mathrm{SH} 2$-domain-containing tyrosine phosphatase (SHP-2) to Tyr759 of gp130, thus inhibiting ERK activation. Interactions of SOCS3 with FAK through the Src homology 2 (SH2) domain have been reported to promote polyubiquitination and subsequent degradation of FAK. Because there are multiple abnormalities in signal transduction and genetic differences in individual patients, SOCS3, which, as seen above, is involved in the regulation of multiple signals, is expected to be effective for the treatment of MPM. However, the potential therapeutic benefits of SOCS3 for MPM have not yet been investigated. In the study presented here, we investigated the efficacy of SOCS3 gene delivery for the treatment of MPM.

\section{Material and Methods \\ Cell lines}

Mesothelioma cell lines H28, H226 and H2452 were purchased from American Type Culture Collection (Manassas, VA). Mesothelioma cell line EHMES-1 was kindly provided by Dr. Hironobu Hamada (Ehime University, Ehime, Japan). ACC-MESO-1 (MESO-1) and ACC-MESO-4 (MESO-4) cell lines were purchased from RIKEN BRC cell bank (Tsukuba, Japan). All the cells were cultured in RPMI 1640 (Wako, Osaka, Japan) with 10\% fetal calf serum (FCS) (HyClone Lab- oratories, Logan, UT), $100 \mathrm{IU} / \mathrm{mL}$ penicillin and $100 \mu \mathrm{g} / \mathrm{mL}$ streptomycin (Nacalai Tesque, Kyoto, Japan). Human adult mesothelial cells were purchased from Zen-Bio (Research Triangle Park, NC) and cultured in Mesothelial Cell Growth Medium (Zen-Bio). HEK293 cells were obtained from the JCRB Cell Bank (Tokyo, Japan) and cultured in DMEM (Wako) with 10\% FCS (HyClone), $100 \mathrm{IU} / \mathrm{mL}$ penicillin and $100 \mu \mathrm{g} / \mathrm{mL}$ streptomycin (Nacalai Tesque).

\section{Reagents}

Recombinant human IL-6 was kindly provided by Dr. Kazuyuki Yoshizaki (Osaka University, Osaka, Japan), recombinant soluble IL-6 receptor (sIL-6R) and anti-IL-6R monoclonal antibody (tocilizumab, currently known as MRA) were obtained from Chugai Pharmaceutical Co. (Tokyo, Japan). Purified human IgG, purchased from Sigma (St. Louis, MO), was used as control for MRA. JAK inhibitor I and PD98059 were purchased from Calbiochem (La Jolla, CA) and doxorubicin from Wako.

\section{Preparation of adenoviruses}

Replication-defective recombinant adenoviral vectors were constructed with the cosmid-adenoviral DNA terminal protein complex method. ${ }^{28}$ Adenoviral vectors AdLacZ and adenovirus-expressing SOCS3 (AdSOCS3) were designed to express the LacZ gene and the human SOCS3 gene, respectively, under the control of the CAG promoter (a modified chicken $\beta$-actin promoter with a cytomegalovirus immediate early enhancer). ${ }^{29-31}$ Solutions of these adenoviral vectors were prepared as described previously and stored at $-80^{\circ} \mathrm{C}$ until use. ${ }^{32}$ Adenoviral vectors containing the genes for HA-tagged $\mathrm{Y705F}$ dominant-negative STAT3 (AddnSTAT3) were kindly provided by Dr. Akihiko Yoshimura (Keio University, Tokyo, Japan).

\section{X-gal staining}

The transduction efficiency of adenoviral vectors was assessed by means of X-gal staining. Cells were cultured in 6-well plates at a density of $1 \times 10^{5}$ cells per well and infected with AdLacZ at the indicated multiplicities of infection (MOIs). $\mathrm{X}$-gal staining was performed $24 \mathrm{hr}$ after infection according to the protocol provided by the manufacturer (SigmaAldrich, St. Louis, MO).

\section{Reverse transcription-polymerase chain reaction analysis}

Total RNA of cultured cells was isolated with Sepasol-RNA I (Nacalai Tesque) and cDNAs were synthesized from $500 \mathrm{ng}$ of each total RNA preparation with a Quantitect Reverse Transcription kit (QIAGEN, Valencia, CA), all according to the manufacturers' instructions. The TaKaRa Ex Taq (Takara Bio, Otsu, Shiga, Japan) was used for reverse transcriptionpolymerase chain reaction (RT-PCR) analysis. $\beta$-actin was used as a housekeeping gene to evaluate and compare the quality of different cDNA samples. Primers for $\beta$-actin $\left(67^{\circ} \mathrm{C}\right.$ annealing, 33 cycles) were: forward, 5'-AGCCTCGCCTTTGCCGA-3'; 
reverse, $5^{\prime}$-CTGGTGCCTGGGGCG- ${ }^{\prime}$. Primers for SOCS3 $\left(55^{\circ} \mathrm{C}\right.$ annealing, 33 cycles) were: forward, $5^{\prime}$-TCAAGACCTTCAGCTCCAAG-3'; reverse, $5^{\prime}$-TTGACGCTGAGCGTGAAGAA$3^{\prime}$. And primers for $\mathrm{p} 53\left(60^{\circ} \mathrm{C}\right.$ annealing, 33 cycles $)$ were: forward, 5'-CCCCAGCCAAAGAGAAACC-3'; reverse, 5' TCCAAGGCCTCATTCAGCTCT- $3^{\prime}$. PCR products were detected by means of $1 \%$ agarose gel electrophoresis with ethidium bromide staining.

\section{Small interfering RNA transfection}

Commercial JAK1 small interfering RNA (siRNA) was obtained from QIAGEN. Cells were transfected with siRNA using Lipofectamine 2000 reagent (Invitrogen, Carlsbad, CA) according to the manufacturer's instructions. Nonspecific siRNA (QIAGEN) was used as a negative control, and the selective silencing of JAK1 was confirmed by Western blot analysis.

\section{Measurement of IL-6 and sIL-6R concentrations in culture supernatant}

MPM cells were cultured in 6-well plates at a density of $1 \times 10^{5}$ cells per well and incubated in RPMI 1640 medium containing $0.5 \%$ FCS. The concentrations of IL- 6 and sIL-6R in the 24-hr culture supernatant were measured by means of Quantikine Colorimetric Sandwich ELISA (R\&D Systems, Minneapolis, MN).

\section{SDS-PAGE and western blot analysis}

Whole cell protein extract was prepared from MPM cells in RIPA buffer $[10 \mathrm{mmol} / \mathrm{L}$ Tris- $\mathrm{HCl}(\mathrm{pH} 7.5), 150 \mathrm{mmol} / \mathrm{L}$ $\mathrm{NaCl}, 1 \%(\mathrm{v} / \mathrm{v}) \mathrm{NP}-40,0.1 \%(\mathrm{w} / \mathrm{v})$ SDS, 0.5\% (w/v) sodium deoxycholate, $1 \mathrm{mmol} / \mathrm{L} \mathrm{Na}_{3} \mathrm{VO}_{4}$, and $1 \times$ protease inhibitor cocktail (Roche Applied Science, Indianapolis, IN)]. Extracted proteins were resolved on SDS-PAGE and transferred to an Immobilon-P Transfer membrane (Millipore, Bedford, MA). The following antibodies were used: antiphospho-STAT3, 1:1,000; anticleaved caspase-3, 1:500; antiphospho-ERK, 1:1,000; anti-ERK, 1:1,000; antiphospho-p53 (Ser46), 1:1,000; antiphospho-p53 (Ser392), 1:1,000 (all from Cell Signaling Technology, Danvers, MA), anti-STAT3, 1:1,000; anti-p53, 1:500; anti-GAPDH, 1:1,000 (all from Santa Cruz Biotechnology, Santa Cruz, CA), antiphospho-FAK (Tyr397) (1:1,000; Biosource, Camarillo, CA), anti-JAK1, 1:1,000; anti-FAK, 1:1,000, anti-p21, 1:1,000 (all from BD Transduction Laboratories, San Jose, CA), antiphosphotyrosine (clone 4G10), 1:1,000 (Upstate Biotechnology, Lake Placid, NY) and antiSOCS3 antibody (1:500; IBL, Gunma, Japan), followed by a 1:5,000 dilution of donkey antirabbit or 1:5,000 dilution of sheep antimouse horseradish peroxidase-conjugated secondary antibodies (GE Healthcare Bio-Sciences, Piscataway, NJ) and visualized with the Western Lightning ECL reagent (Perkin-Elmer, Boston, MA).

\section{Immunoprecipitation}

Cells were lysed in ice-cold RIPA buffer. After clearing of the lysate, anti-p53 antibody (Cell Signaling Technology) was added to the lysate followed by overnight incubation at $4^{\circ} \mathrm{C}$. Protein G Sepharose (GE Healthcare Bio-Sciences) was then added and incubated by end-over-end mixing for $2 \mathrm{hr}$. The beads were washed five times in RIPA buffer and analyzed by Western blotting.

\section{Phospho-kinase array}

Expression of phosphorylated proteins was detected with the Proteome Profiler ${ }^{\mathrm{TM}}$ Human Phospho-Kinase Array kit (R\&D Systems). The procedures were performed according to the manufacturer's protocol using $400 \mu \mathrm{g}$ protein lysate per array.

\section{MTS assay}

MPM cell lines were plated in 96-well plates at a density of 1,000 cells per well and incubated in RPMI 1640 medium containing $10 \%$ FCS. After a three-day culture, cell proliferation was evaluated with the 3-(4,5-dimethylthiazol-2-yl)-5(3-carboxymethoxyphenyl)-2-(4-sulfophenyl)-2H-tetrazolium (MTS) assay (CellTiter 96 aqueous nonradioactive cell proliferation assay; Promega, Madison, WI). MTS color development was measured and analyzed with a microplate reader Model 680 (Bio-Rad Laboratories, Hercules, CA) at a wavelength of $450 \mathrm{~nm}$ with a reference wavelength of $750 \mathrm{~nm}$. This assay was performed in triplicate.

\section{Apoptosis assay}

MPM cells were grown to confluence to attain synchronization in G1 and subcultured at a lower density $\left(1 \times 10^{5}\right.$ cells in a six-well plate) for $24 \mathrm{hr}$ so that most of the cells were in the $S$ phase. Adenoviral vectors were infected by distributing suspensions of AdSOCS3 or AdLacZ onto cells at a MOI of 40 , followed by incubation at $37^{\circ} \mathrm{C}$ for an additional $72 \mathrm{hr}$. The cells were then trypsinized and collected with the supernatants, followed by determination of cell viability by means of annexin $\mathrm{V}$ and 7-amino-actinomycin $\mathrm{D}$ (7-AAD) staining (BD Biosciences, San Jose, CA) using the FACSCanto flow cytometer (BD Biosciences). Data were analyzed with FlowJo software (Tree Star, Ashland, OR). This assay was performed in duplicate.

\section{Cell cycle assay}

MPM cells were grown to confluence to attain synchronization in G1 and subcultured at a lower density $\left(1 \times 10^{5}\right.$ cells in a six-well plate) for $24 \mathrm{hr}$ so that most of the cells were in the $S$ phase. Adenoviral vectors were infected by distributing suspensions of AdSOCS3 or AdLacZ onto cells at an MOI of 40 , followed by incubation at $37^{\circ} \mathrm{C}$ for an additional $24 \mathrm{hr}$. The cells were then trypsinized and collected with the supernatants, after which the cell cycle was determined by means of propidium iodide (PI) staining according to the instructions for the Cycle Test Plus DNA Reagent kits (BD Biosciences) using the FACSCanto flow cytometer. This assay was performed in duplicate. 

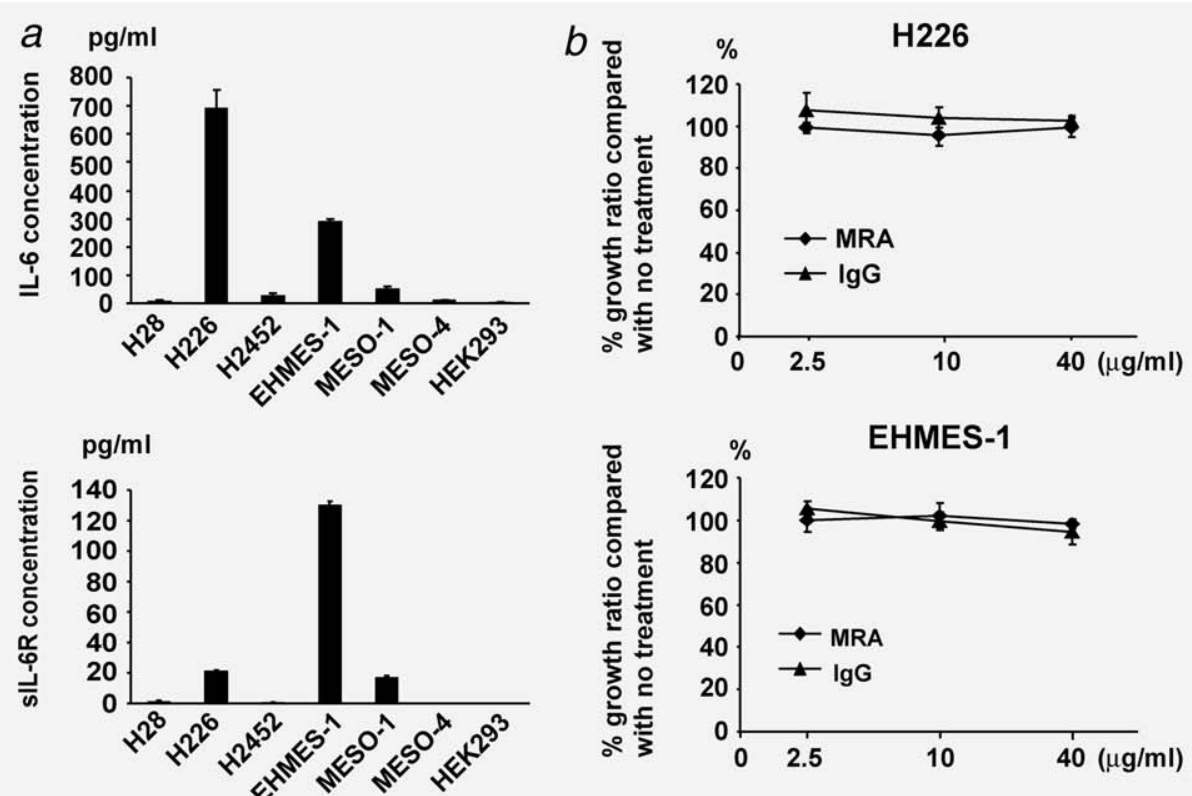

Figure 1. MRA treatment does not inhibit the growth of MPM cells. (a) IL-6 and sIL-6R concentrations were measured by using sandwich ELISA. Results are shown as average (columns) + SD (bars). (b) Growth curves of H226 and EHMES-1 cells treated with MRA. Cells were cultured in RPMI medium containing 10\% FCS with $2.5-40 \mu \mathrm{g} / \mathrm{mL}$ MRA or human IgG. After a 3-day culture, viable cell numbers were counted with the MTS assay. Figures show the average (points) of triplicate wells \pm SD (bars). (c) Inhibition of phosphor-STAT3 by MRA. H226 and EHMES-1 cells were cultured in RPMI medium containing $0.5 \%$ FCS with $2.5-40 \mu \mathrm{g} / \mathrm{mL}$ MRA or human IgG. After a 24-hr culture, the phosphorylation of STAT3 in MPM cells was analyzed after 10-min stimulation with $100 \mathrm{ng} / \mathrm{mL}$ of IL-6 and $100 \mathrm{ng} / \mathrm{mL}$ of slL-6R. The lysates from IL-6- and sIL-6R-stimulated cells were analyzed by means of Western blot with antiphospho STAT3 antibody, and subsequently with anti-STAT3 and anti-GAPDH antibody.

\section{Mouse xenograft model}

All animal experiments were conducted according to the institutional ethical guidelines for animal experimentation of the National Institute of Biomedical Innovation (Osaka, Japan). Female ICR $n u / n u$ mice, 6 to 7 weeks of age, were obtained from Charles River Japan (Yokohama, Japan). The mice were housed for 7 to 14 days and allowed ad libitum access to food and water.

For subcutaneous xenograft experiments, we injected $3 \times 10^{6}$ cells in a total volume of $100 \mu \mathrm{L}$ of $1 / 1(\mathrm{v} / \mathrm{v})$ PBS/ Matrigel (Becton Dickinson, Bedford, MA) in the flank of ICR $n u / n u$ mice. When the tumor sizes reached $\sim 100 \mathrm{~mm}^{3}, 1 \times 10^{8}$ plaque-forming units (pfu)/50 $\mu \mathrm{L}$ of AdSOCS3 or AdLacZ was injected intratumorally twice per week. Tumor volumes were determined weekly by measuring in two dimensions, length $(L)$ and width $(W)$, and calculating volume as $\left(W^{2} \times L\right) / 2$.

For pleural xenograft experiments, cells were resuspended in PBS at a density of $1 \times 10^{6}$ cells in a total volume of $150 \mu \mathrm{L}$ of $1 / 1(\mathrm{v} / \mathrm{v})$ PBS/Matrigel (Becton Dickinson). The mice were intrathoracically injected with $150 \mu \mathrm{L}$ of the cell suspension through a 26-gauge needle. Seven, 14 and 21 days after cell inoculation, $5.0 \times 10^{7}$ plaque-forming units (pfu)/ 


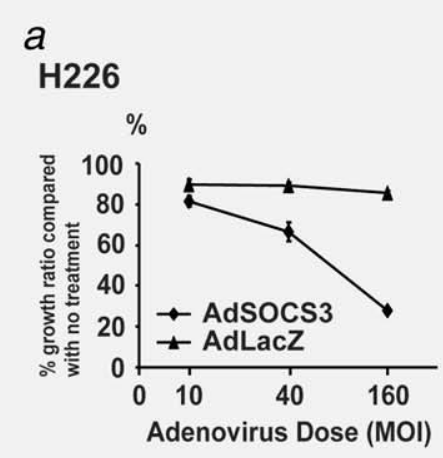

\section{EHMES-1}

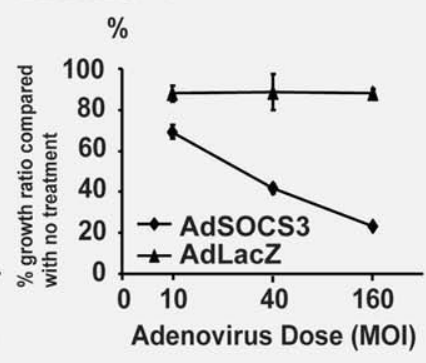

MESO-1

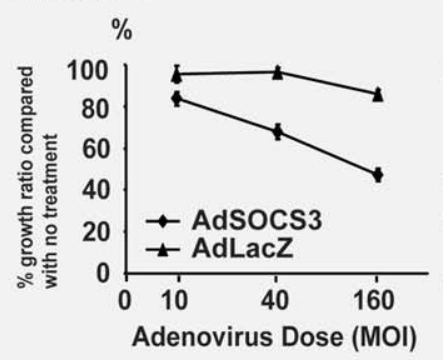

c

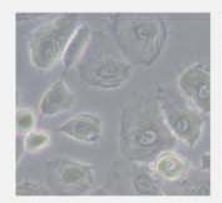

Untreated

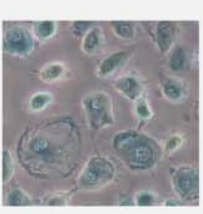

MOI 10

\section{MESO-4}
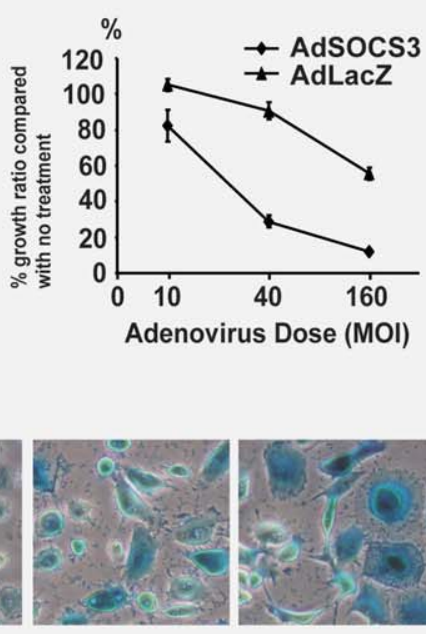

MOI 40

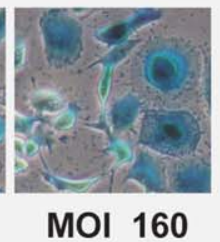

$b$

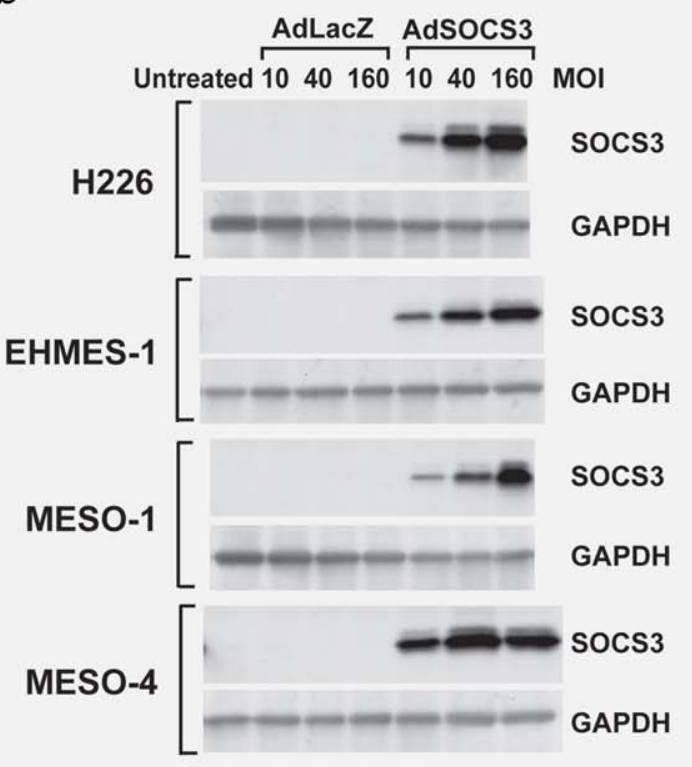

$d$

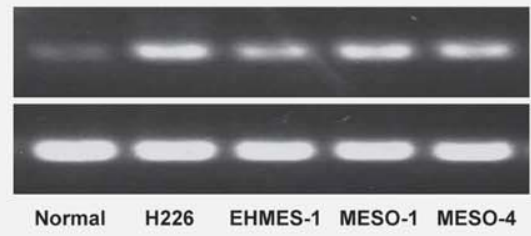

socs3

$\beta$-actin

Figure 2. Overexpression of SOCS3 inhibits the growth of MPM cells. (a) Growth curves of MPM cells treated with AdSOCS3. Cells were infected with either AdSOCS3 or AdLacZ as control at an MOI of 10-160. Cells were cultured in RPMI 1640 medium containing $10 \%$ FCS. After a 3-day culture, viable cell numbers were counted with the MTS assay. Figures show the average (points) of triplicate wells \pm SD (bars). (b) Expression of SOCS3 as a result of transduction of AdSOCS3. Cells were infected with either AdSOCS3 or AdLacZ as control at an MOI of 10-160. Cells were cultured in RPMI 1640 medium containing $10 \%$ FCS. After a 24-hr culture, the cell lysates were analyzed by means of Western blotting using anti-SOCS3 antibody and subsequently with anti-GAPDH antibody. (c) Transduction efficiency of the adenoviral vector in $\mathrm{H} 226$ cells. $\mathrm{H} 226$ cells were infected with AdLacZ at the indicated MOI and stained with X-gal 24 hr after infection.

(d) Expression of endogenous SOCS3. RT-PCR was used for the assessment of SOCS3 expression.

$150 \mu \mathrm{L}$ of AdSOCS3 or AdLacZ was injected into the thoracic space with the same technique. Twenty-eight days after cell inoculation, the mice were sacrificed and their thoracic spaces examined macroscopically for growths, and tumors detected in the thoracic spaces were removed and weighed.

\section{Immunohistochemistry}

Tumors in the thoracic spaces were harvested and paraffin embedded for immunohistochemical analysis using antiSOCS3 antibody (IBL). Terminal deoxynucleotidyl transferase-mediated dUTP nick-end labeling (TUNEL) assay (with DAPI nuclear counterstaining) for apoptosis was performed using the ApopTag® Fluorescein in situ Apoptosis Detection Kit (Chemicon International, Temecula, CA) according to the manufacturer's instructions.

\section{Statistical analysis}

Data are shown as mean \pm SD for the number of experiments indicated. Student's $t$-test was used for comparison of the data. Differences were considered significant at $p<0.05$.

\section{Results}

\section{MRA treatment has no inhibitory effect on the growth of} MPM cells

Reports of high-level expression of IL- 6 in the pleural fluid of MPM patients prompted us to investigate the role of this signaling pathway in MPM. To characterize IL-6/sIL-6R levels secreted by MPM cell lines, we used sandwich ELISA for quantitation of IL-6/sIL-6R levels in 24-hr culture supernatants. As shown in Figure $1 a, \mathrm{H} 226$ and EHMES-1 were identified as cell lines with high IL-6/sIL-6R secretion. 

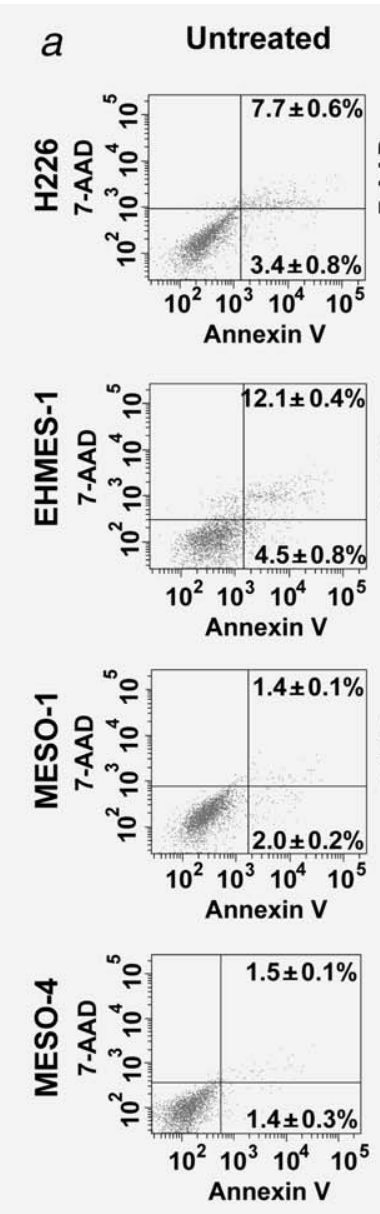

AdLacZ
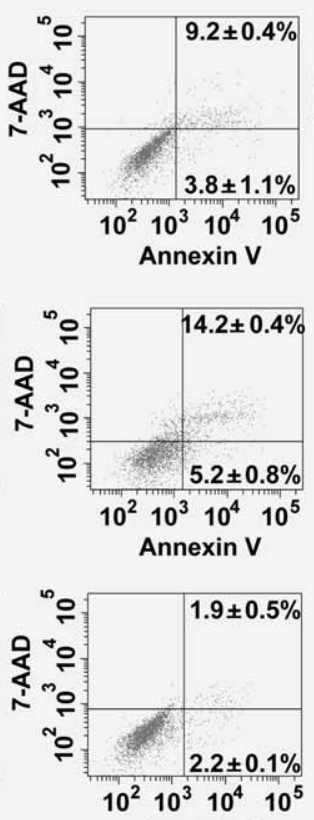

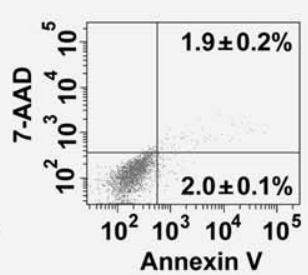

AdSOcs3
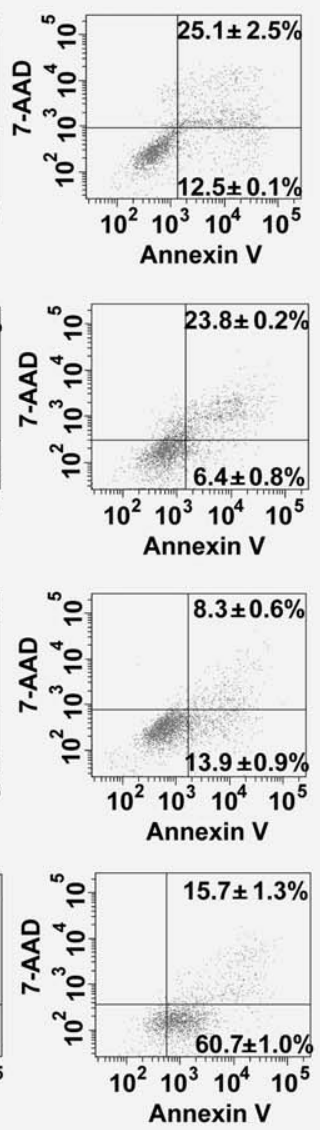

$b$
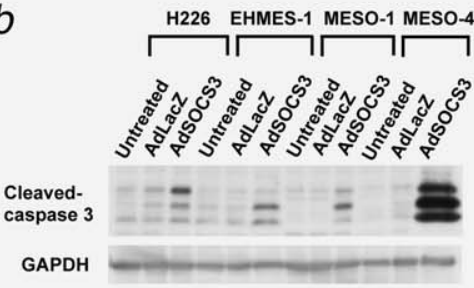

$C$
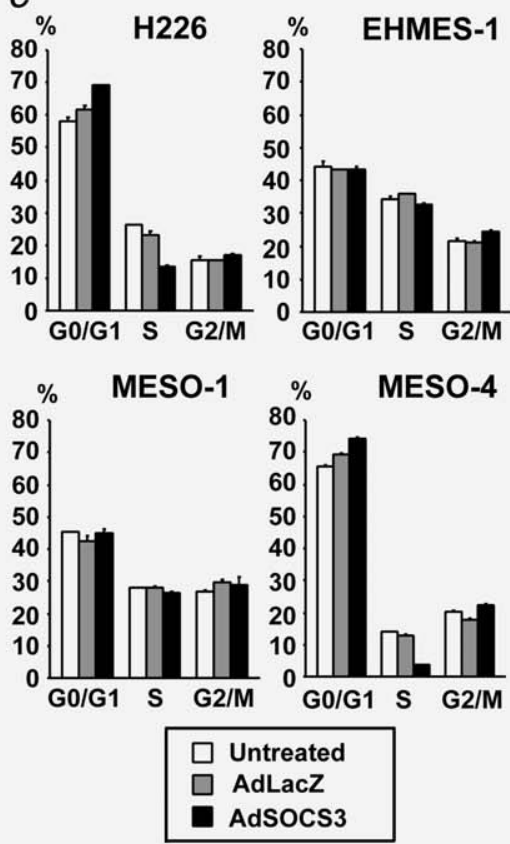

Figure 3. SOCS3 induces apoptosis and G0/G1 arrest in MPM cells. (a) Cells were infected with either AdSOCS3 or AdLacZ as control at an $\mathrm{MOI}$ of 40. Cells were cultured in RPMI 1640 medium containing $10 \%$ FCS for 3 days. Apoptosis was determined by means of annexin $\mathrm{V}$ and 7-AAD staining using flow cytometry. Figures show the average of duplicate wells \pm SD. (b) Cells were infected with either AdSOCS3 or AdLacZ as control at an MOI of 40. Cells were cultured in RPMI 1640 medium containing $10 \%$ FCS for 3 days. Whole cell extracts were prepared and immunoblotted with anticleaved caspase-3 antibody. (c) Cells were infected with either AdSOCS3 or AdLacZ as control at an MOI of 40. Cells were cultured in RPMI 1640 medium containing $10 \%$ FCS for $24 \mathrm{hr}$. The cell cycle was determined by means of propidium iodide (PI) staining using flow cytometry. Figures show the average (columns) of duplicate wells + SD (bars).

Because it has been reported that IL-6 may represent a therapeutic target for tumorigenesis in MPM cells, ${ }^{12}$ we subsequently tested the effect of anti-IL-6R monoclonal antibody (MRA) treatment. For this analysis, we used H226 and EHMES- 1 cells which secrete high levels of IL-6. Figure $1 b$ shows that MRA did not inhibit cell growth in H226 and EHMES-1 cells. On the other hand, it has been reported that $25 \mu \mathrm{g} / \mathrm{mL}$ of MRA is required for sufficient growth suppression of Lennert's lymphoma-derived T cells which show IL6-dependent cell growth ${ }^{12}$ and we demonstrated that MRA inhibited IL-6-stimulated STAT3 phosphorylation in MPM cells (Fig. 1c). These results suggest that, although H226 and EHMES-1 cells secreted high levels of IL-6, IL-6 signaling had little effect on the growth of these cells. However, the role of STAT3 on cell growth in H226 and EHMES-1 cells was not clear since MRA treatment did not inhibit endogenous phosphorylated STAT3 levels in these cells.

\section{Overexpression of SOCS3 inhibits the growth of MPM cells}

The JAK/STAT3 pathway is an important signaling pathway negatively regulated by SOCS3. We therefore used a replication-defective recombinant adenoviral vector to investigate the regulation of MPM cell growth by SOCS3. As shown in Figure $2 a$, AdSOCS3 strongly inhibited cell growth in H226, EHMES-1, MESO- 1 and MESO- 4 cells, while the endogenous SOCS3 expression levels of MPM cells were higher than those of normal mesothelial cells (Fig. 2d). This indicates that overexpression of SOCS3 was required for growth inhibition of MPM cells. Because sufficient transduction efficiency of the adenovirus vector and strong expression of 


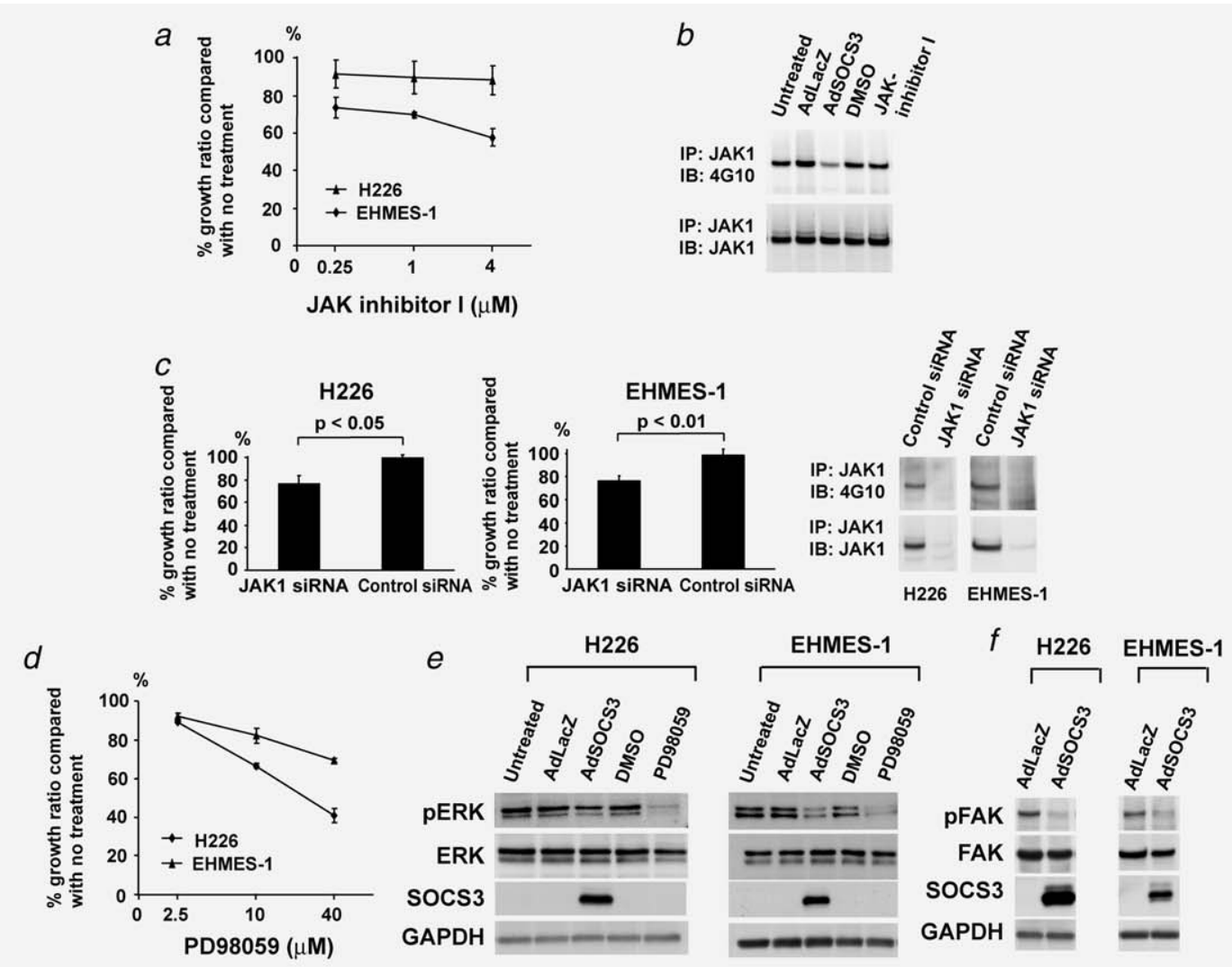

Figure 4. SOCS3 inhibits JAK1, ERK and FAK signaling. (a) Growth curves of H226 and EHMES-1 cells treated with JAK inhibitor I. Cells were cultured in RPMI 1640 medium containing 10\% FCS with 0.25-4 $\mu \mathrm{M}$ JAK inhibitor I or dimethyl sulfoxide (DMSO) (untreated). After a 3-day culture, viable cell numbers were counted with the MTS assay. Figures show the average (points) of triplicate wells \pm SD (bars). (b) Inhibition of JAK1 phosphorylation by AdSOCS3. H226 cells were cultured in RPMI 1640 medium containing $0.5 \%$ FCS with $1 \mu$ M JAK inhibitor I or AdSOCS3 at an MOI of 40 . After $24 \mathrm{hr}$ of culturing, $100 \mathrm{ng} / \mathrm{mL}$ of IL- 6 and $100 \mathrm{ng} / \mathrm{mL}$ of sIL-6R were added for $10 \mathrm{~min}$ and protein extracts were immunoprecipitated with anti-JAK1 antibody and blotted with antiphosphotyrosine antibody (clone 4G10). (c) Growth of $\mathrm{H} 226$ and EHMES-1 cells treated with JAK1 siRNA. Cells were treated with either JAK1 siRNA or nonspecific siRNA as control. Cells were cultured in RPMI 1640 medium containing $0.5 \%$ FCS, $100 \mathrm{ng} / \mathrm{mL}$ of IL-6 and $100 \mathrm{ng} / \mathrm{mL}$ of slL-6R. After a 3-day culture, viable cell numbers were counted with the MTS assay. Figures show the average (columns) of triplicate wells + SD (bars). Protein extracts were immunoprecipitated with anti-JAK1 antibody and blotted with antiphosphotyrosine antibody (clone 4G10) and subsequently with anti-JAK1 antibody. (d) Growth curves of H226 and EHMES-1 cells treated with PD98059. Cells were cultured in RPMI 1640 medium containing $10 \%$ FCS with 2.5-40 $\mu$ M PD98059 or dimethyl sulfoxide (DMSO) (untreated). After a 6-day culture, viable cell numbers were counted with the MTS assay. Figures show the average (points) of triplicate wells \pm SD (bars). (e) Inhibition of ERK phosphorylation by AdSOCS3. H226 and EHMES-1 cells were cultured in RPMI 1640 medium containing 0.5\% FCS with $4 \mu \mathrm{M}$ PD98059 or AdSOCS3 at an MOI of 40 . After 24 hr of culturing, protein extracts were blotted with antiphospho-ERK antibody. ( $f)$ Negative regulation of FAK signaling by SOCS3. H226 and EHMES-1 cells were cultured in RPMI 1640 medium containing 10\% FCS with AdSOCS3 at an MOI of 40 . After 24 hr of culturing, cells were cultured in RPMI 1640 medium containing 0.5\% FCS for an additional $24 \mathrm{hr}$. Protein extracts were blotted with antiphospho-FAK antibody.

SOCS3 were detected at an MOI of 40 in MPM cells (Figs. $2 b$ and $2 c$ ), we performed subsequent experiments using AdSOCS3 at an MOI of 40.

\section{SOCS3 induces apoptosis and G0/G1 arrest in MPM cells} Next, we investigated the mechanism by which AdSOCS3 inhibited cell growth in H226, EHMES-1, MESO-1 and
MESO-4 cells. Since light microscopy findings suggested poor cell viability, apoptosis in these cells was tested by means of annexin $\mathrm{V}$ and 7 -AAD staining using flow cytometry three days after the addition of AdSOCS3 to the culture. The results of flow cytometric analysis led to the identification of two types of cells: early apoptotic $\left(A n n e x i n V^{+} 7-\mathrm{AAD}^{-}\right.$) and late apoptotic (Annexin $\mathrm{V}^{+} 7-\mathrm{AAD}^{+}$). Compared to treatment with AdLacZ, treatment with AdSOCS3 resulted in elevated 
a

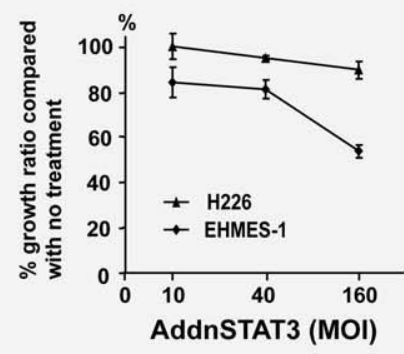

b AdLacZ

AddnSTAT3

AdSOcs3

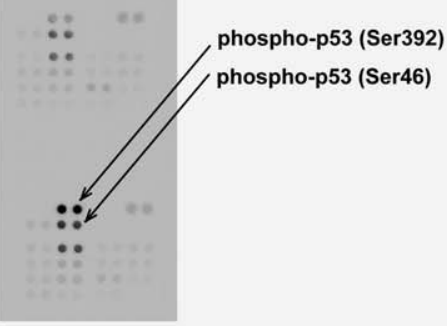

c

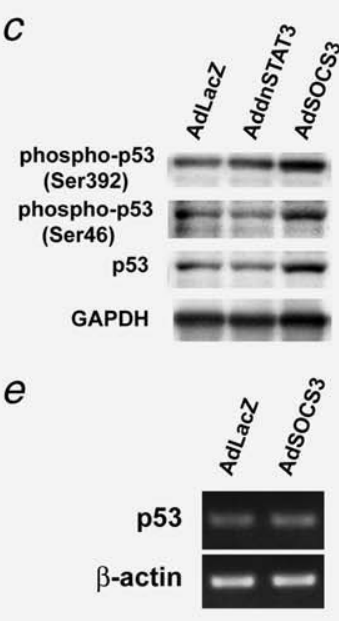

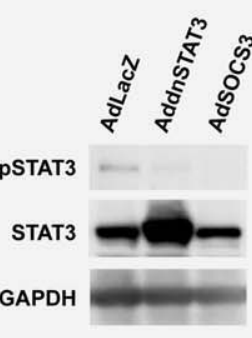

$d$

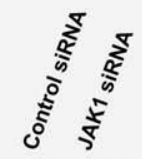

phospho-p53
(Ser392) (Ser392)
phospho-p53 (Ser46)

$$
\text { p53 }
$$

GAPDH

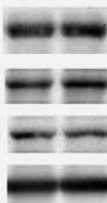

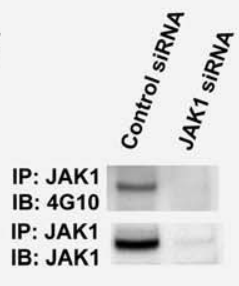

IB: JAK1

IP: p53

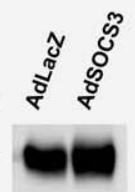

p53

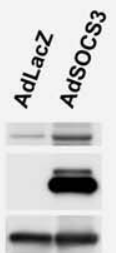

IB: p53

IB: socs3
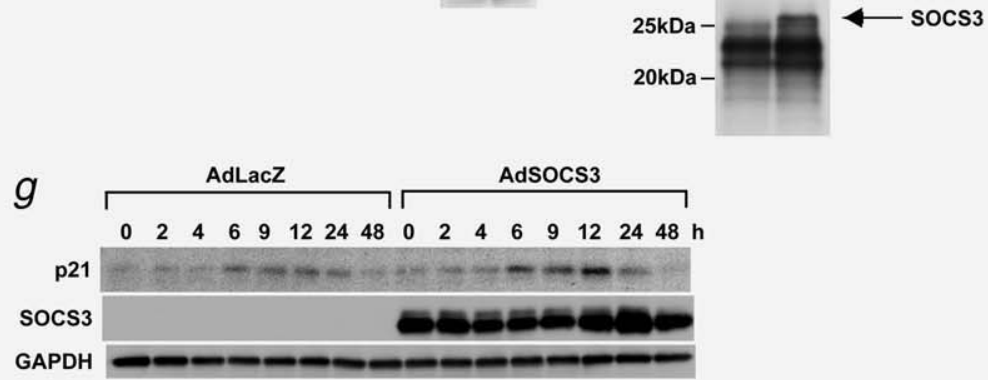

Figure 5. SOCS3 regulates p53 expression in a STAT3-independent manner. (a) Growth curves of H226 and EHMES-1 cells treated with AddnSTAT3. Cells were infected with either AddnSTAT3 or AdLacZ as control at an MOI of 10-160. Cells were cultured in RPMI 1640 medium containing $10 \%$ FCS. After a 3-day culture, viable cell numbers were counted with the MTS assay. Figures show the average (points) of triplicate wells \pm SD (bars). (b) Phospho-kinase array revealed that $\mathrm{H} 226$ cells treated with AdSOCS3 showed higher levels of phospho-p53 (Ser 392) and phospho-p53 (Ser 46) expression than those treated with AddnSTAT3 or AdLacZ. H226 cells were cultured in RPMI 1640 medium containing 0.5\% FCS with AdSOCS3 at an MOI of 40. After $24 \mathrm{hr}$ of culturing, protein extracts were examined with a phospho-kinase array with each phosphorylated protein identified in duplicate. The double-labeled spots in the upper right corner represent the positive controls. (c) p53 expression was induced by AdSOCS3. H226 cells were cultured in RPMI 1640 medium containing $0.5 \%$ FCS with AdSOCS3 at an MOI of 40 . After $24 \mathrm{hr}$ of culturing, protein extracts were probed with antiphospho-p53 (Ser 392), phosphop53 (Ser 46), p53, phospho-STAT3, STAT3 and GAPDH antibody. (d) Influence of JAK1 siRNA on p53 expression. Either JAK1 siRNA or nonspecific siRNA as control was added to $\mathrm{H} 226$ cells. Cells were cultured in RPMI 1640 medium containing $0.5 \%$ FCS. After $48 \mathrm{hr}$ of culturing, $100 \mathrm{ng} / \mathrm{mL}$ of IL-6 and $100 \mathrm{ng} / \mathrm{mL}$ of sIL-6R were added for $10 \mathrm{~min}$. The protein extracts were probed with antiphospho-p53 (Ser 392), phospho-p53 (Ser 46), p53 and GAPDH antibody or immunoprecipitated with anti-JAK1 antibody and blotted with antiphosphotyrosine antibody (clone 4G10) and subsequently with anti-JAK1 antibody. (e) Expression of p53. RT-PCR was used to determine levels of p53 expression. (f) SOCS3 interacts with p53. H226 cells were cultured in RPMI 1640 medium containing $10 \%$ FCS with AdSOCS3 at an MOI of 40 . After $24 \mathrm{hr}$ of culturing, protein extracts were immunoprecipitated with anti-p53 antibody and immunoblotted with anti-SOCS3 antibody. (g) SOCS3 enhances p21 expression. H226 cells were cultured in RPMI 1640 medium containing $10 \%$ FCS with AdSOCS3 at an $\mathrm{MOI}$ of 40 . After $12 \mathrm{hr}$ of culturing, $\mathrm{H} 226$ cells were treated with doxorubicin $(300 \mathrm{ng} / \mathrm{mL})$ for $0-48 \mathrm{hr}$. Protein extracts were immunoblotted with anti-p21 antibody. 
apoptosis in both early and late apoptotic subsets in H226, EHMES-1, MESO-1 and MESO-4 cells (Fig. 3a). Furthermore, cleaved caspase-3, one of the key molecules in apoptosis, was detected in whole cell extracts of H226, EHMES-1, MESO-1 and MESO-4 cells treated with AdSOCS3 (Fig. 3b). We therefore conclude that AdSOCS3 induced apoptosis in MPM cells.

In addition to apoptosis, cell cycle regulation is an important mechanism for inhibition of cell growth. To analyze the effect of AdSOCS3 on cell cycle regulation, we infected H226, EHMES-1, MESO-1 and MESO-4 cells with AdSOCS3 and then analyzed cell cycle distribution by means of flow cytometry. When H226 and MESO-4 cells were treated with AdSOCS3, the G0/G1 cell population increased more than in those treated with AdLacZ (Fig. 3c).

\section{SOCS3 inhibits JAK1, ERK and FAK signaling}

One of the important signaling pathways regulated by SOCS3 is the JAK/STAT3 pathway. We used JAK inhibitor I, which suppresses JAK2 signaling, to investigate the regulation of cell growth by JAK signaling pathways. For this assay, we used H226 and EHMES-1 cell lines (on which MRA had no growth inhibitory effect) to investigate the IL6-independent growth inhibitory effect by SOCS3. As shown in Figure $4 a$, only the growth of EHMES-1 cells, and not of H226 cells, was inhibited by JAK inhibitor I. This suggests that AdSOCS3 inhibited cell growth in H226 cells via signaling pathways which were not inhibited by JAK inhibitor I.

To identify the differences between the inhibitory effects of AdSOCS3 and JAK inhibitor I on JAK signaling pathways, we studied changes in the phosphorylation status of JAK1 in H226 cells treated with AdSOCS3 and JAK inhibitor I. Figure $4 b$ shows that AdSOCS3 suppressed IL-6-stimulated JAK1 phosphorylation, but that JAK inhibitor I did not affect it. These results lead us to propose that SOCS3 inhibited cell growth in $\mathrm{H} 226$ in part by means of negative regulation of JAK1.

We used JAK1 siRNA to evaluate the role of JAK1 signaling pathways in cell growth. As seen in Figure $4 c$, JAK1 siRNA inhibited cell growth in H226 and EHMES-1 cells, suggesting that the growth of H226 cells was partially regulated by JAK1 signaling.

Because it has been reported that SOCS3 inhibits the ERK and FAK signalling pathways, we examined these pathways in H226 and EHMES-1 cells. Figure $4 d$ demonstrated that the growth of H226 and EHMES-1 cells was inhibited by the ERK inhibitor PD98059, while ERK phosphorylation was inhibited by AdSOCS3 in these cells (Fig. 4e). In addition, AdSOCS3 inhibited phospho-FAK and FAK in H226 and EHMES-1 cells (Fig. 4f). We therefore conclude that overexpression of SOCS3 regulates multiple signaling pathways in MPM cells.

\section{SOCS3 regulates p53 expression}

We next investigated the role of STAT3 in $\mathrm{H} 226$ and EHMES-1 cells and used AddnSTAT3 to examine the regulation of cell growth by STAT3 signaling pathways. As seen in Figure $5 a$, AddnSTAT3 inhibited cell growth in EHMES1 cells but not in $\mathrm{H} 226$ cells. Since this suggests that STAT3 is not involved in the growth of H226 cells, we focused our study on signaling pathways independent of STAT3.

To identify the target molecules of SOCS3 in STAT3-independent pathways, we used a phospho-kinase array to evaluate the expression profile of phosphorylated proteins in H226 cells. Figure $5 b$ shows that expression of phospho-p53 (Ser 392) and phospho-p53 (Ser 46) in H226 cells after treatment with AdSOCS3 was higher than in those treated with either AddnSTAT3 or AdLacZ. In addition to phospho-p53, p53 was also highly expressed when treated with AdSOCS3 (Fig. 5c). These results suggest that SOCS3 regulated p53 expression.

We next investigated whether JAK1 regulates p53 expression. To this end, we used JAK1 siRNA for the transfection of H226 cells and Western blotting for the examination of p53 expression. As shown in Figure $5 d$, silencing of JAK1 did not influence p53 expression, indicating that JAK1 and p53 are regulated by SOCS3 via independent pathways.

Since transfection with AdSOCS3 did not enhance transcription of p53 in $\mathrm{H} 226$ cells (Fig. 5e), we next investigated whether SOCS3 interacts with p53. After transfection of AdSOCS3 into H226 cells, we detected SOCS3 in the immunoprecipitate of a p53-specific antibody (Fig. 5f). In addition, SOCS3 enhanced the expression of p21 which was the target of p53 (Fig. $5 g$ ). Taken together, these findings suggest that SOCS3 interacts with p53 protein.

\section{SOCS3 exhibits antitumor activity in a mesothelioma xenograft model}

We also evaluated the therapeutic effect of AdSOCS3 injection on the growth of subcutaneously or intrathoracically implanted MPM cells in ICR $n u / n u$ mice. Of the MPM cell lines used in our study, we were able to establish H226 and MESO-4 xenograft models. Injection of AdSOCS3 vector $\left(1 \times 10^{8} \mathrm{pfu} / 50 \mu \mathrm{L}\right)$ intratumorally twice per week reduced tumor volumes compared to tumor volumes in control AdLacZ-injected animals (Fig. 6a). Preliminary experiments revealed that when $1 \times 10^{6} \mathrm{MPM}$ cells (H226 or MESO-4) were inoculated into the thoracic space, dissemination of tumors was observed in all mice 28 days after cell implantation. Injection of the AdSOCS3 vector $\left(5 \times 10^{7} \mathrm{pfu} / 150 \mu \mathrm{L}\right)$ into the thoracic cavity 7, 14 and 21 days after the implantation of $1 \times 10^{6}$ MPM cells (H226 or MESO-4), reduced the weight of tumor nodules compared to the weight of those in control AdLacZ-injected animals (Figs. $6 b$ and $6 c$ ). Finally, Western blot and immunohistochemical analysis indicated that SOCS3 was overexpressed and induced apoptosis in the 


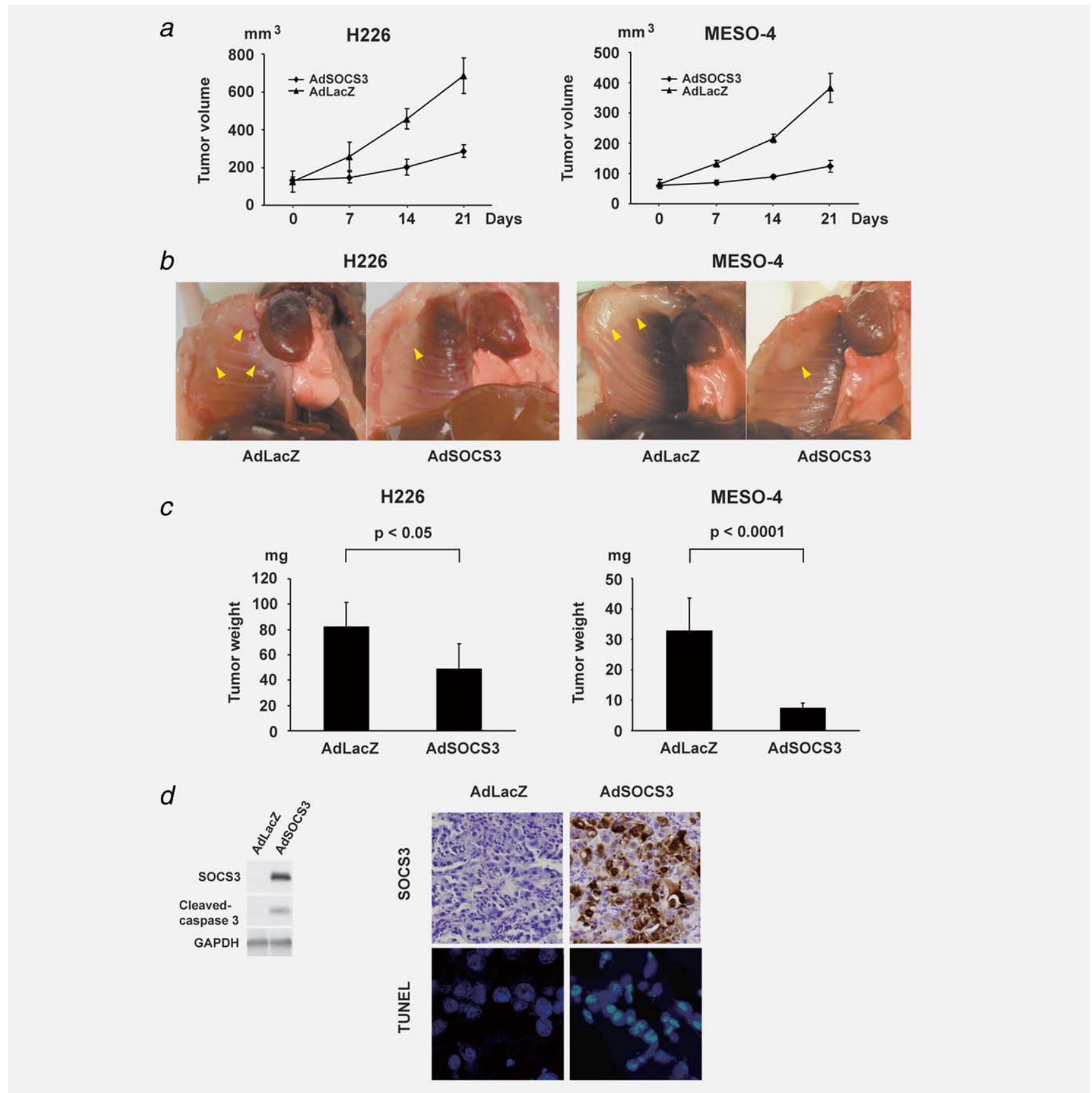

Figure 6. SOCS3 exhibits antitumor activity in a mesothelioma xenograft model. (a) Female ICR nu/nu mice were intratumorally treated with $1 \times 10^{8}$ pfu of AdSOCS3 or AdLacZ twice per week after the implantation of $3 \times 10^{6}$ H226 or MESO-4 cells subcutaneously in the flank of mice. Tumor volumes were determined weekly. Figures show the average (points) for five animals \pm SD (bars). (b) Gross appearance of H226 and MESO-4 tumors grown orthotopically in the thoracic spaces. Female ICR nu/nu mice were intrathoracically treated with $5 \times 10^{7}$ pfu of AdSOCS3 or AdLacZ for 7, 14 and 21 days after the implantation of $1 \times 10^{6} \mathrm{H} 226$ or MESO-4 cells into the pleural space. After 28 days of tumor cell inoculation, the animals were sacrificed and pleural dissemination of the tumor cells was assessed. (c) Each tumor nodule found in the thoracic spaces was also weighed. Figures show the average (columns) for eight animals + SD (bars). (d) Western blot analysis of SOCS3 and cleaved caspase-3 in H226 tissue from AdSOCS3-injected animals (left panel). The H226 cell bearing animals were treated with AdSOCS3 on day 7 and sacrificed on day 10. The thoracic tumors were analyzed by Western blot. Immunohistochemical analysis of SOCS3 and TUNEL (blue fluorescence = DAPI staining for nuclei; cyan fluorescence = TUNEL positivity) in H226 tissue from AdSOCS3-injected animals (right panel). The animals were treated in the same way as described above. 
H226 tissue from AdSOCS3-injected animals (Fig. 6d). Immunohistochemical analysis of SOCS3 overexpression and apoptosis in MESO-4 tissue could not be clearly determined, however Western blot analysis showed identical results to that observed in H226 tissue (data not shown). From these results, we conclude that SOCS3 exhibits antitumor activity not only in vitro but also in vivo in the MPM model. We hope that these findings may lead to the successful clinical application of SOCS3 for MPM treatment.

\section{Discussion}

Malignant mesothelioma represents a great challenge to both clinicians and researchers due to its poor prognosis and remarkable resistance to current therapies. Although there have been some improvements in treatment over the past few years, a better understanding of the molecular basis of the disease and of how to improve treatment is required. Among molecular targeted therapies, recently developed tyrosine kinase inhibitors have been tested for MPM but without therapeutic benefit. This is partially explained by the fact that multiple receptor tyrosine kinases are frequently activated in most MM cells. ${ }^{23}$ In our study, we showed that SOCS3 inhibited the proliferation of MPM cells through multiple signaling pathways including JAK/STAT3, ERK, FAK and p53 pathways. We observed that SOCS3 did not influence the expression and activation of p38, JNK, Akt or GSK3 $\beta$ proteins in H226 and EHMES-1 cell lines (data not shown). Specifically, we were able to demonstrate that AdSOCS3 inhibits MPM progression in a mouse pleural xenograft model. These data provide new insights into the clinical application of SOCS3 gene delivery for the treatment of MPM.

We also provided evidence that MRA had little effect on proliferation of MPM cells. A recent study by Adachi et al. ${ }^{12}$ found that MRA is capable of blocking IL-6 signaling and suppresses the cell growth of MPM induced by IL-6/sIL-6R. We hypothesize that MRA was not able to inhibit proliferation of these cells because it did not inhibit signals from other cytokines acting through gp130 or endogenous activated molecules downstream of gp130 involved in proliferation of these cells.

There are several JAK inhibitors, including JAK inhibitor $\mathrm{I}^{33}$ but these inhibitors inhibit JAK1 less than they do other JAK family molecules. This may explain why, although JAK1 is involved in $\mathrm{H} 226$ cell proliferation, JAK inhibitor I had little effect on proliferation of $\mathrm{H} 226$ cells. SOCS3, however, is an effective JAK1 inhibitory molecule and also inhibits proliferation of H226 cells. It has further been reported that JAK2 inhibitors have antitumor effects on various cancer cells. ${ }^{34}$ Because of its pan-JAK inhibitory effect, ${ }^{20}$ SOCS3 appears to be a promising antitumor molecule.

We were able to show that SOCS3 regulated phospho-p53 (Ser392 and Ser46) and total p53 expression. Functional inac- tivation of the p53 pathways appears to be a critical requirement for the development of several human cancers. ${ }^{35}$ In spite of the fact that mutations in p53 are among the most commonly acquired genetic lesions seen in cancers, p53 mutations are rarely seen in MPM including H226 cells. ${ }^{36}$ It has been reported that Ser392 phosphorylation may regulate the oligomerization of p53 and thus its sequence-specific DNA binding, ${ }^{37,38}$ while phosphorylation of Ser46 has been implicated in the activation of p53-dependent apoptotic responses. $^{39,40}$ The most thoroughly characterized downstream target of p53 activation is the induction of p21 expression, with p21 playing a critical role in the cell cycle checkpoint. ${ }^{41}$ In our study, moreover, SOCS3 enhanced p21 expression and induced apoptosis and G0/G1 arrest in MPM cells. In view of these results, we propose that SOCS3 induces apoptosis as well as G0/G1 arrest partially through the p53 pathways in MPM cells.

Recently, it has been reported that SOCS1 activates p53 via a direct interaction between the $\mathrm{SH} 2$ domain of SOCS1 and the $\mathrm{N}$-terminal transactivation domain of $\mathrm{p} 53,{ }^{42}$ while we were able to show that SOCS3 did not enhance transcription of p53 but interacted with p53. It is thus conceivable that the observed interaction of SOCS3 with p53 may in turn enhance p53 protein stability. Such a mechanism may therefore involve the inhibition of interaction of $\mathrm{p} 53$ with other proteins that promote $\mathrm{p} 53$ protein degradation.

In our study, we used adenoviral SOCS3 gene transfer to the thoracic cavity in a mouse xenograft pleural tumor model to provide evidence of a potent antitumor effect of SOCS3 in vivo. Because MPM locates within the thoracic cavity and rarely displays widespread metastasis, gene transfer to the thoracic cavity makes this tumor uniquely accessible, thus facilitating the direct administration of novel therapeutic agents and subsequent analysis of treatment effects. Clinical trials involving intrapleural administration of adenoviral vectors to MPM patients have demonstrated that intrapleural gene therapy using adenoviral vectors is safe and well tolerated by MPM patients. ${ }^{43,44}$

In conclusion, we demonstrated the antitumor effect of SOCS3 against MPM both in vitro and in vivo. The results of clinical application of SOCS3 for MPM treatment are eagerly anticipated.

\section{Acknowledgements}

This work was supported by a Grant-in-Aid from the Ministry of Health, Labour and Welfare, Japan (T. Naka), a Grant-in-Aid for Young Scientists (B) from the Ministry of Education, Culture, Sports, Science and Technology, Japan (K. Iwahori) and a grant from the Kansai Biomedical Cluster Project in Saito, which is promoted by the Knowledge Cluster Initiative of the Ministry of Education, Culture, Sports, Science and Technology, Japan (T. Naka). We wish to thank Akihito Yokoyama (Kochi University, Kochi, Japan) and Hironobu Hamada (Ehime University, Ehime, Japan) for providing helpful comments on this article, and Namiko Kawakami and Yukako Ito for their secretarial assistance. 


\section{References}

1. Vogelzang NJ, Rusthoven JJ, Symanowski J, Denham C, Kaukel E, Ruffie P, Gatzemeier U, Boyer M, Emri S, Manegold C, Niyikiza C, Paoletti P. Phase III study of pemetrexed in combination with cisplatin versus cisplatin alone in patients with malignant pleural mesothelioma. J Clin Oncol 2003;21:2636-44.

2. Pelucchi C, Malvezzi M, La Vecchia C, Levi F, Decarli A, Negri E. The Mesothelioma epidemic in Western Europe: an update. Br J Cancer 2004;90: 1022-4.

3. Leigh J, Driscoll T. Malignant mesothelioma in Australia, 1945-2002. Int J Occup Environ Health 2003;9:206-17.

4. Leithner K, Leithner A, Clar H, Weinhaeusel A, Radl R, Krippl P, Rehak P, Windhager R, Haas OA, Olschewski H. Mesothelioma mortality in Europe: impact of asbestos consumption and simian virus 40. Orphanet J Rare Dis 2006;1:44.

5. Murayama T, Takahashi K, Natori Y, Kurumatani N. Estimation of future mortality from pleural malignant mesothelioma in Japan based on an agecohort model. Am J Ind Med 2006;49:1-7.

6. Fitzpatrick DR, Peroni DJ, BielefeldtOhmann H. The role of growth factors and cytokines in the tumorigenesis and immunobiology of malignant mesothelioma. Am J Respir Cell Mol Biol 1995;12:455-60.

7. Galffy G, Mohammed KA, Dowling PA, Nasreen N, Ward MJ, Antony VB. Interleukin 8: an autocrine growth factor for malignant mesothelioma. Cancer Res 1999;59:367-71.

8. Lee TC, Zhang Y, Aston C, Hintz R, Jagirdar J, Perle MA, Burt M, Rom WN. Normal human mesothelial cells and mesothelioma cell lines express insulin-like growth factor I and associated molecules. Cancer Res 1993;53:2858-64.

9. Morocz IA, Schmitter D, Lauber B, Stahel RA. Autocrine stimulation of a human lung mesothelioma cell line is mediated through the transforming growth factor alpha/epidermal growth factor receptor mitogenic pathway. Br J Cancer 1994;70: 850-6.

10. Versnel MA, Claesson-Welsh L, Hammacher A, Bouts MJ, van der Kwast TH, Eriksson A, Willemsen R, Weima SM, Hoogsteden HC, Hagemeijer A, et al. Human malignant mesothelioma cell lines express PDGF beta-receptors whereas cultured normal mesothelial cells express predominantly PDGF alpha-receptors. Oncogene 1991;6:2005-11.

11. Monti G, Jaurand MC, Monnet I, Chretien P, Saint-Etienne L, Zeng L, Portier A, Devillier P, Galanaud P, Bignon J, et al.
Intrapleural production of interleukin 6 during mesothelioma and its modulation by gamma-interferon treatment. Cancer Res 1994;54:4419-23.

12. Adachi Y, Aoki C, Yoshio-Hoshino N, Takayama K, Curiel DT, Nishimoto N. Interleukin- 6 induces both cell growth and VEGF production in malignant mesotheliomas. Int J Cancer 2006;119: 1303-11.

13. Buettner R, Mora LB, Jove R. Activated STAT signaling in human tumors provides novel molecular targets for therapeutic intervention. Clin Cancer Res 2002;8: 945-54.

14. Endo TA, Masuhara M, Yokouchi M, Suzuki R, Sakamoto H, Mitsui K, Matsumoto A, Tanimura S, Ohtsubo M, Misawa H, Miyazaki T, Leonor N, et al. A new protein containing an $\mathrm{SH} 2$ domain that inhibits JAK kinases. Nature 1997;387: 921-4.

15. Naka T, Narazaki M, Hirata $M$, Matsumoto T, Minamoto S, Aono A, Nishimoto N, Kajita T, Taga T, Yoshizaki K, Akira S, Kishimoto T. Structure and function of a new STAT-induced STAT inhibitor. Nature 1997;387:924-9.

16. Starr R, Willson TA, Viney EM, Murray LJ, Rayner JR, Jenkins BJ, Gonda TJ, Alexander WS, Metcalf D, Nicola NA, Hilton DJ. A family of cytokine-inducible inhibitors of signalling. Nature 1997;387: 917-21.

17. Rakesh K, Agrawal DK. Controlling cytokine signaling by constitutive inhibitors. Biochem Pharmacol 2005;70: 649-57.

18. Naka T, Fujimoto M, Tsutsui $H$, Yoshimura A. Negative regulation of cytokine and TLR signalings by SOCS and others. Adv Immunol 2005;87:61-122.

19. Yoshimura A, Naka T, Kubo M. SOCS proteins, cytokine signalling and immune regulation. Nat Rev Immunol 2007;7: 454-65.

20. Nicholson SE, De Souza D, Fabri LJ, Corbin J, Willson TA, Zhang JG, Silva A, Asimakis M, Farley A, Nash AD, Metcalf D, Hilton DJ, et al. Suppressor of cytokine signaling-3 preferentially binds to the SHP2-binding site on the shared cytokine receptor subunit gp130. Proc Natl Acad Sci USA 2000;97:6493-8.

21. He B, You L, Uematsu K, Zang K, Xu Z, Lee AY, Costello JF, McCormick F, Jablons DM. SOCS-3 is frequently silenced by hypermethylation and suppresses cell growth in human lung cancer. Proc Natl Acad Sci USA 2003;100: 14133-8.

22. Bromberg J. Stat proteins and oncogenesis. J Clin Invest 2002;109:1139-42.
23. Sekido Y. Genomic abnormalities and signal transduction dysregulation in malignant mesothelioma cells. Cancer Sci 2010;101:1-6.

24. Poulikakos PI, Xiao GH, Gallagher R, Jablonski S, Jhanwar SC, Testa JR. Reexpression of the tumor suppressor NF2/ merlin inhibits invasiveness in mesothelioma cells and negatively regulates FAK. Oncogene 2006;25: 5960-8.

25. Lehmann U, Schmitz J, Weissenbach M, Sobota RM, Hortner M, Friederichs K, Behrmann I, Tsiaris W, Sasaki A, Schneider-Mergener J, Yoshimura A, Neel BG, et al. SHP2 and SOCS3 contribute to Tyr-759-dependent attenuation of interleukin-6 signaling through gp130. J Biol Chem 2003;278:661-71.

26. Liu E, Cote JF, Vuori K. Negative regulation of FAK signaling by SOCS proteins. EMBO J 2003;22:5036-46.

27. Niwa $Y$, Kanda H, Shikauchi Y, Saiura A, Matsubara K, Kitagawa T, Yamamoto J, Kubo T, Yoshikawa H. Methylation silencing of SOCS-3 promotes cell growth and migration by enhancing JAK/STAT and FAK signalings in human hepatocellular carcinoma. Oncogene 2005; 24:6406-17.

28. Miyake S, Makimura M, Kanegae Y, Harada S, Sato Y, Takamori K, Tokuda C, Saito I. Efficient generation of recombinant adenoviruses using adenovirus DNAterminal protein complex and a cosmid bearing the full-length virus genome. Proc Natl Acad Sci USA 1996;93: 1320-4.

29. Kijima T, Osaki T, Nishino K, Kumagai T, Funakoshi T, Goto H, Tachibana I, Tanio Y, Kishimoto T. Application of the Cre recombinase/loxP system further enhances antitumor effects in cell type-specific gene therapy against carcinoembryonic antigenproducing cancer. Cancer Res 1999;59: 4906-11.

30. Goto H, Osaki T, Kijima T, Nishino K, Kumagai T, Funakoshi T, Kimura H, Takeda Y, Yoneda T, Tachibana I, Hayashi S. Gene therapy utilizing the Cre/loxP system selectively suppresses tumor growth of disseminated carcinoembryonic antigenproducing cancer cells. Int J Cancer 2001; 94:414-9.

31. Nishino K, Osaki T, Kumagai T, Kijima T, Tachibana I, Goto H, Arai T, Kimura H, Funakoshi T, Takeda Y, Tanio Y, Hayashi S. Adenovirus-mediated gene therapy specific for small cell lung cancer cells using a Myc-Max binding motif. Int $J$ Cancer 2001;91:851-6.

32. Kanegae Y, Makimura M, Saito I. A simple and efficient method for purification of 
infectious recombinant adenovirus. Jpn J Med Sci Biol 1994;47:157-66.

33. Lipka DB, Hoffmann LS, Heidel F, Markova B, Blum MC, Breitenbuecher F, Kasper S, Kindler T, Levine RL, Huber C Fischer T. LS104, a non-ATP-competitive small-molecule inhibitor of JAK2, is potently inducing apoptosis in JAK2V617F-positive cells. Mol Cancer Ther 2008;7:1176-84.

34. Verstovsek S, Manshouri T, QuintasCardama A, Harris D, Cortes J, Giles FJ, Kantarjian H, Priebe W, Estrov Z. WP1066, a novel JAK2 inhibitor, suppresses proliferation and induces apoptosis in erythroid human cells carrying the JAK2 V617F mutation. Clin Cancer Res 2008;14:788-96.

35. Vazquez A, Bond EE, Levine AJ, Bond GL. The genetics of the p53 pathway, apoptosis and cancer therapy. Nat Rev Drug Discov 2008;7:979-87.

36. Yonesaka K, Tamura K, Kurata T, Satoh T, Ikeda M, Fukuoka M, Nakagawa K. Small interfering RNA targeting survivin sensitizes lung cancer cell with mutant p53 to adriamycin. Int J Cancer 2006;118: 812-20.

37. Sakaguchi K, Sakamoto H, Lewis MS, Anderson CW, Erickson JW, Appella E, Xie D. Phosphorylation of serine 392 stabilizes the tetramer formation of tumor suppressor protein p53. Biochemistry 1997; 36:10117-24.

38. Hao M, Lowy AM, Kapoor M, Deffie A, Liu G, Lozano G. Mutation of phosphoserine 389 affects p53 function in vivo. J Biol Chem 1996;271:29380-5.

39. D’Orazi G, Cecchinelli B, Bruno T, Manni I, Higashimoto Y, Saito S, Gostissa M, Coen S, Marchetti A, Del Sal G, Piaggio G, Fanciulli M, et al. Homeodomaininteracting protein kinase-2 phosphorylates p53 at Ser 46 and mediates apoptosis. Nat Cell Biol 2002;4:11-9.

40. Saito S, Goodarzi AA, Higashimoto Y, Noda Y, Lees-Miller SP, Appella E, Anderson CW. ATM mediates phosphorylation at multiple p53 sites, including Ser(46), in response to ionizing radiation. J Biol Chem 2002; 277:12491-4.
41. Abbas T, Dutta A. p21 in cancer: intricate networks and multiple activities. Nat Rev Cancer 2009;9:400-14.

42. Calabrese V, Mallette FA, DeschenesSimard X, Ramanathan S, Gagnon J, Moores A, Ilangumaran S, Ferbeyre G. SOCS1 links cytokine signaling to p53 and senescence. Mol Cell 2009;36:754-67.

43. Sterman DH, Recio A, Carroll RG, Gillespie CT, Haas A, Vachani A, Kapoor V, Sun J, Hodinka R, Brown JL, Corbley MJ, Parr M, et al. A phase I clinical trial of single-dose intrapleural IFN-beta gene transfer for malignant pleural mesothelioma and metastatic pleural effusions: high rate of antitumor immune responses. Clin Cancer Res 2007;13: 4456-66.

44. Sterman DH, Recio A, Vachani A, Sun J, Cheung L, DeLong P, Amin KM, Litzky LA, Wilson JM, Kaiser LR, Albelda SM. Long-term follow-up of patients with malignant pleural mesothelioma receiving high-dose adenovirus herpes simplex thymidine kinase/ganciclovir suicide gene therapy. Clin Cancer Res 2005;11:7444-53. 